Aim of the study: The worldwide population shift towards older ages will inevitably lead to more elderly patients being diagnosed with nonsmall cell lung cancer (NSCLC). It still remains controversial whether sublobar resection is effective in such cases at an early stage. To answer this question, we need to understand the clinical characteristics of these tumors.

Material and methods: From 2004 to 2010 , a total of 167 patients with stage I non-small cell lung cancer (NSCLC) of age $\geq 70$ years underwent complete resection in our institution. The clinical data were retrospectively analyzed as regards gender, stage of disease, histology, smoking status, smoking amount, drinking status, surgical approaches and overall survival. Survival was analyzed by the Kaplan-Meier method and log-rank test.

Results: The overall 5-year survival rate was $62.4 \%$. There were $122(73.1 \%)$ patients who underwent standard lobectomy resection and $45(26.9 \%)$ patients underwent sublobar resection. Patients with different surgical approaches (lobectomy and sublobar resection) had nearly the same 5 -year survival rate $(60.9 \%$ vs. $63.4 \%$, $p=0.558)$. Gender $(p=0.023)$, smoking status $(p=0.045)$ and smoking amount ( $p=0.007)$ significantly influenced the prognosis.

Conclusions: In elderly stage I NSCLC patients, sublobar resection is considered to be an appropriate treatment in comparison with lobectomy, as this procedure provides equivalent longterm survival.

Key words: elderly, non-small cell lung cancer (NSCLC), surgical resection, sublobar resection.

Contemp Oncol (Pozn) 2014; 18 (2): 111-115 DOI: $10.5114 /$ wo.2014.42726

\section{Early lung cancer in the elderly: sublobar resection provides equivalent long-term survival in comparison with lobectomy}

Tieqin Liu, Hongxu Liu, Yu Li

Department of Thoracic Surgery, First Hospital, China Medical University, Shenyang, PR China

\section{Introduction}

Lung cancer is the most common cancer and the leading cause of cancer deaths in the world [1]. Surgery is considered the treatment of choice in patients with early-stage NSCLC [2]. Over the past decade, lobectomy has been the standard surgical procedure. Sublobar resection such as wedge resection and segmentectomy could be indicated in patients with stage I NSCLC, who may tolerate operative intervention but not a lobectomy resection because of comorbid disease or decreased cardiopulmonary function [3]. In recent years, retrospective studies have shown that the long-term outcome of sublobar resection is comparable to that of lobectomy [4]. Therefore, the management and determination of the appropriate operative approach for elderly patients with stage I NSCLC need an understanding of the characteristics of these tumors.

\section{Material and methods}

Patients

From 2004 to 2010, a total of 167 patients with stage I NSCLC of age $\geq 70$ years underwent a thoracotomy in the Department of Thoracic Surgery, First Hospital, China Medical University. Preoperatively, patients underwent a thorough physical examination and blood examination, respiratory function test, electrocardiogram, bone scintigraphy, bronchoscopic examination and computed tomography of the brain and chest. Their clinical data were retrospectively reviewed. Variables used for evaluation were gender, stage, histology, smoking status, smoking amount, drinking status, surgical approaches and overall survival.

\section{Methods}

After resection, the tumors were pathologically examined during the operation with frozen section. Patients were pathologically staged according to the International Union Against Cancer (UICC) staging system for lung cancer ( $7^{\text {th }}$ ed.) [5]. Histological subtypes of resected specimens were determined according to the World Health Organization classification of 2009. The type of surgery was categorized into two groups according to the extent of the pulmonary resection: standard surgery including a lobar resection and sublobar resection such as segmentectomy and wedge resection. A sublobar resection was indicated for high risk cases, including insufficient pulmonary function $\left(F E V_{1}<1.5\right)$ or chronic lung diseases, insufficient cardiac function (LVEF $<50 \%$ ) or cardiovascular diseases, or previous lung surgery (greater than lobectomy). 
Table 1. Clinical characteristics of 167 patients aged $\geq 70$

\begin{tabular}{|c|c|c|c|}
\hline Variable & No. of patients & 5-year survival rate & $P$-value \\
\hline Total & 167 & $62.4 \%$ & \\
\hline $\begin{array}{l}\text { Gender } \\
\text { female } \\
\text { male }\end{array}$ & $\begin{array}{l}71(42.5 \%) \\
96(57.5 \%)\end{array}$ & $\begin{array}{l}84.2 \% \\
49.5 \%\end{array}$ & 0.023 \\
\hline Median age (range; years) & $69(65-84)$ & & \\
\hline $\begin{array}{l}\text { Histology } \\
\text { adenocarcinoma } \\
\text { squamous carcinoma } \\
\text { others }\end{array}$ & $\begin{array}{c}98(58.7 \%) \\
62(37.1 \%) \\
7(4.2 \%)\end{array}$ & $\begin{array}{l}63.8 \% \\
61.4 \% \\
57.5 \%\end{array}$ & 0.749 \\
\hline $\begin{array}{l}\text { Surgical procedure } \\
\text { lobectomy } \\
\text { sublobar resection }\end{array}$ & $\begin{array}{l}122(73.1 \%) \\
45(26.9 \%)\end{array}$ & $\begin{array}{l}60.9 \% \\
63.4 \%\end{array}$ & 0.558 \\
\hline $\begin{array}{l}\text { Pathological stage } \\
\text { IA } \\
\text { IB }\end{array}$ & $\begin{array}{c}51(30.5 \%) \\
116(69.5 \%)\end{array}$ & $\begin{array}{l}70.6 \% \\
58.7 \%\end{array}$ & 0.370 \\
\hline $\begin{array}{l}\text { Smoking status } \\
\text { smokers } \\
\text { nonsmokers }\end{array}$ & $\begin{array}{l}77(46.1 \%) \\
90(53.9 \%)\end{array}$ & $\begin{array}{l}55.0 \% \\
68.3 \%\end{array}$ & 0.045 \\
\hline $\begin{array}{l}\text { Drinking status } \\
\text { drinkers } \\
\text { nondrinkers }\end{array}$ & $\begin{array}{c}32(19.2 \%) \\
135(80.8 \%)\end{array}$ & $\begin{array}{l}58.1 \% \\
63.3 \%\end{array}$ & 0.302 \\
\hline $\begin{array}{l}\text { Smoking amount } \\
\qquad P^{1} \leq 20 \\
P Y>20\end{array}$ & $\begin{array}{l}48(28.7 \%) \\
119(71.3 \%)\end{array}$ & $\begin{array}{l}72.2 \% \\
39.5 \%\end{array}$ & 0.007 \\
\hline
\end{tabular}

PY: Pack-years (PY) were defined as the number of cigarette packs (20 cigarettes per pack) smoked per day multiplied by years of smoking and used to quantify smoking history.

Smoking amount was pack-years smoked (PY). Packyears smoked was defined as the number of cigarette packs (20 cigarettes per pack) smoked per day multiplied by years of smoking and used to quantify smoking history.

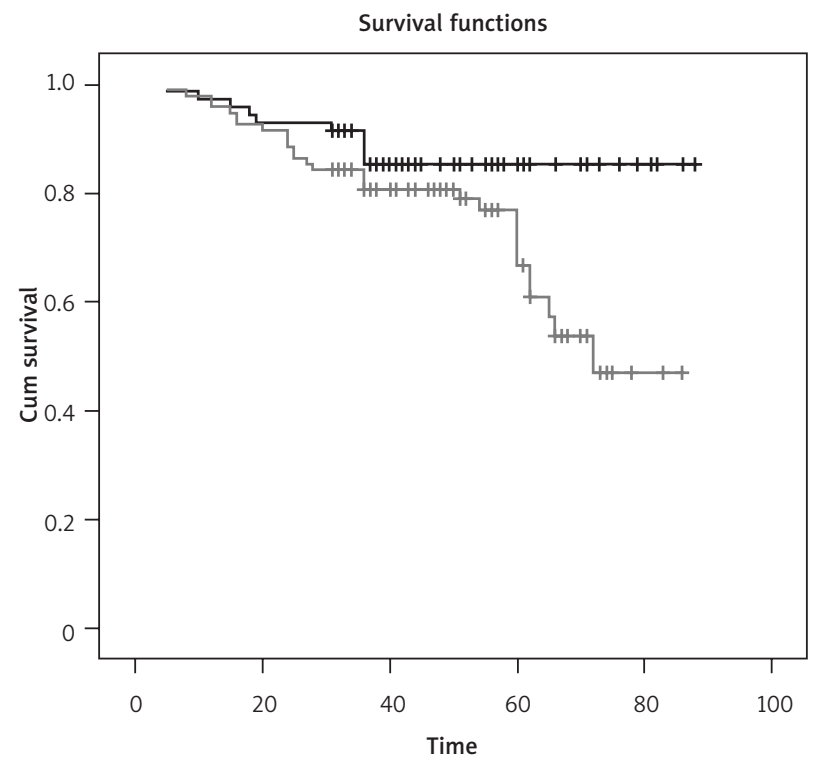

Gender

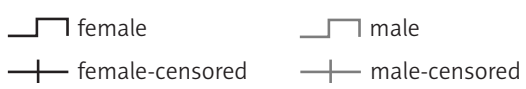

Fig. 1. Kaplan-Meier survival analysis based on gender

\section{Statistical analyses}

Survival curves were constructed using the Kaplan-Meier method and compared using the log-rank test. A Cox proportional hazard model was used to identify relevant variables affecting survival. Median values were shown with the 95\% confidence interval (CI). Statistical analysis was performed with SPSS 16.0 software (SPSS Inc, Chicago, IL). Significance was set at $P$ of less than 0.05 . The overall survival time was calculated from the day of the surgery to the latest follow-up date.

\section{Results}

The clinical findings are shown in Table 1. There was no mortality or morbidity in both groups within the first 30 days. The overall 5 -year survival rate was $62.4 \%$, whereas that for females was $84.2 \%$ and that for males was 49.5\% ( $p=0.023$ ) (Fig. 1). Of the 167 patients, 90 patients (53.9\%) had no history of smoking at any time in their life as compared to 77 (46.1\%) patients who had smoked. Concerning the smoking status, the 5-year survival rate for nonsmokers was $68.3 \%$, which was better than that for smokers (55.0\%); there was a statistical difference $(p=0.045)$ (Fig. 2). The overall 5-year survival rates of these patients with 20 or less PY smoking history and greater than 20 PY smoking history were $72.2 \%$ and $39.5 \%$ ( $p=0.007$; Fig. 3). The 5 -year survival rate for drinkers was $58.1 \%$, whereas it was $63.3 \%$ for nondrinkers $(p=0.302)$. The multivariate Cox proportional hazards analysis revealed that gender was associated with the hazard ratio of $0.380(0.180-0.805 ; p=0.012)$ (Table 2). 


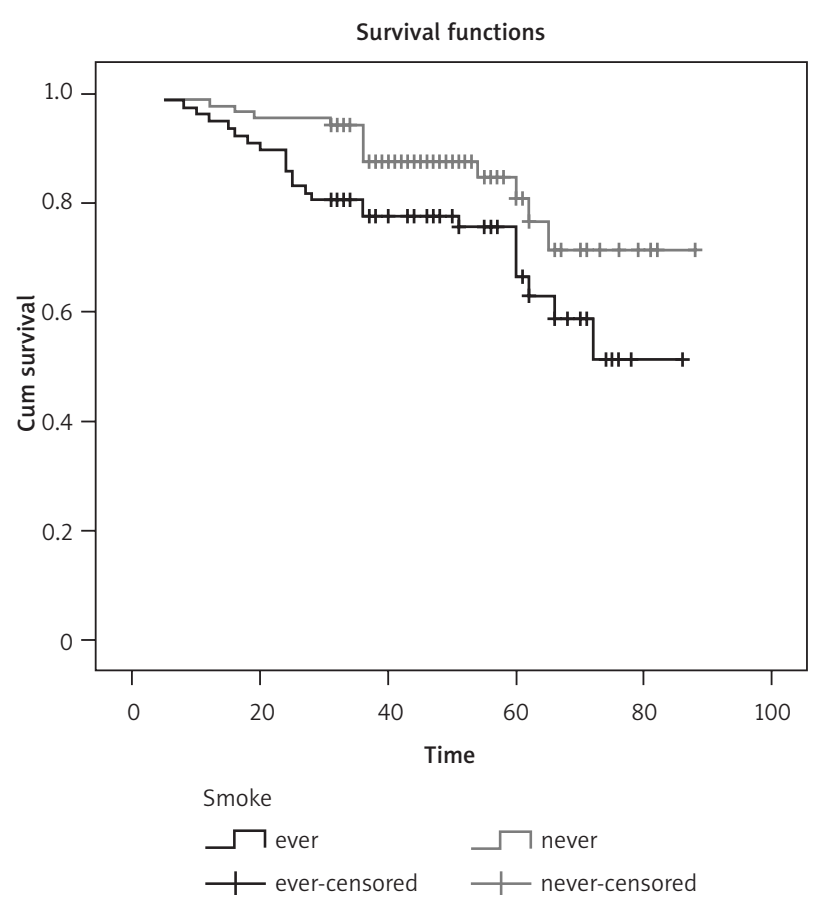

Fig. 2. Kaplan-Meier survival analysis based on smoking status

There was no significant difference of the 5-year survival rate in different histology, age and surgical approaches. In this study, a total of 122 (73.1\%) patients underwent lobectomy resection, and 45 (26.9\%) cases underwent sublobar resection. Patients receiving lobectomy had nearly the same survival rate as patients receiving sublobar resection (60.9\% vs. $63.4 \%, p=0.558)$. Fifty-one $(30.5 \%)$ patients at stage IA had a 5-year survival rate of $70.6 \%$, and 116 (69.5\%) patients at stage IB had a 5-year survival rate of $58.7 \%(p=0.370)$. The tumor histology was as follows: adenocarcinoma in 98 (58.7\%) patients; squamous cell carcinoma in 62 (37.1\%); others in 7 (4.2\%). The 5 -year survival rate for patients with adenocarcinoma was $63.8 \%$, whereas it was $61.4 \%$ for those with squamous cell carcinoma $(p=0.749)$.

\section{Discussion}

Lung cancer has been the most commonly diagnosed cancer annually since 1985 [6]. With the increasing age of the global population, the number of elderly patients with NSCLC has increased. However, the surgical treatment of NSCLC in elderly patients remains challenging. In a prospective study conducted in 1995, Ginsberg et al. found that patients with early stage (T1NO) non-small cell lung cancer (NSCLC) who underwent limited resection had a higher locoregional recurrence and higher mortality rates than those who underwent lobectomy, and they concluded that lobectomy should be the standard surgery for stage I NSCLC [7]. Over the past decade, lobectomy combined with lymph node dissection has been the standard surgical procedure for stage I NSCLC. As aging results in physiological changes in the cardiovascular and respiratory systems, the frequency of other underlying diseases increases. Surgical resection for NSCLC itself has a possibil-

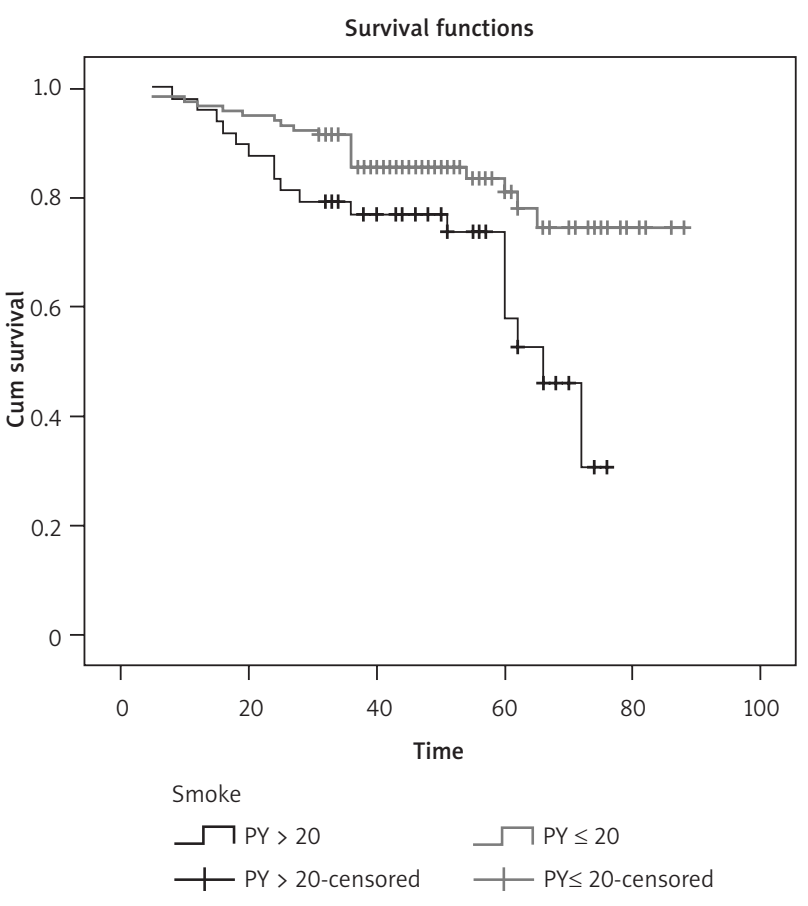

Pack-years (PY) were defined as the number of cigarette packs (20 cigarettes per pack) smoked per day multiplied by years of smoking and used to quantify smoking history.

Fig. 3. Kaplan-Meier survival analysis based on pack-years (PY)

Table 2. Results of the multivariate analysis of patient characteristics (Cox proportional hazards model)

\begin{tabular}{lccc} 
Variables & $\begin{array}{c}\text { Hazard } \\
\text { ratio }\end{array}$ & $\begin{array}{c}95 \% \mathrm{Cl} \\
P \text {-value }\end{array}$ & $P$-value \\
$\begin{array}{l}\text { Age } \\
\geq 70\end{array}$ & 1.044 & $0.520-2.098$ & 0.903 \\
$\begin{array}{l}\text { Gender } \\
\text { female }\end{array}$ & 0.380 & $0.180-0.805$ & 0.012 \\
$\begin{array}{l}\text { Smoking status } \\
\text { never-smokers }\end{array}$ & 0.761 & $0.259-2.234$ & 0.619 \\
$\begin{array}{c}\text { Smoking amount } \\
\quad \text { PY }>\text { 20 }\end{array}$ & 1.432 & $0.890-2.305$ & 0.139 \\
$\begin{array}{c}\text { Alcohol status } \\
\text { never-drink }\end{array}$ & 0.957 & $0.419-2.183$ & 0.916 \\
$\begin{array}{c}\text { Surgical procedure } \\
\text { sublobar resection }\end{array}$ & 0.737 & $0.350-1.552$ & 0.422 \\
\hline $\begin{array}{c}\text { Stage } \\
\text { stage IA }\end{array}$ & 0.678 & $0.321-1.432$ & 0.309
\end{tabular}

Smoking amount ${ }^{1}$ : Pack-years (PY) were defined as the number of cigarette packs (20 cigarettes per pack) smoked per day multiplied by years of smoking and used to quantify smoking history.

ity of increasing the risk of life-threatening complications, and the mortality rate reported ranges from $2.8 \%$ to $3.7 \%$ [8]. Thus surgeons often hesitate to recommend lobectomy for patients under comorbid conditions or with poor pulmonary function. Instead, sublobar resection such as wedge resection and segmentectomy is often offered to those patients in daily clinical practice to reduce surgical stress and to preserve more pulmonary function. In recent years, retrospective studies have shown that the long- 
term outcome of sublobar resection is comparable to that of lobectomy. In 2010, Okami and his colleagues conducted a retrospective study and did not find any significant differences in 5-year survival rates between lobectomy and sublobar resection in lung cancer patients aged more than 75 years. The authors concluded that sublobar resection is the indicated surgical procedure for these patients [4]. In our study, there was a better result in the survival for sublobar resection than lobectomy. Patients who received sublobar resection had less trauma and less immune function damage, and thus they recovered quickly. This finding suggests that local control for primary early NSCLC should be considered in patients with high surgical risk or poor cardio-pulmonary functional reserve, especially for the elderly.

Cigarette smoking is a well-known risk factor in lung cancer [9]. Whether smoking-related lung cancer behaves more aggressively or results in poorer survival than lung cancer not related to smoking remains unclear. There may be several possible explanations for the highly aggressive and invasive biologic pulmonary characteristics in patients with greater than 20 PY smoking history. Cigarette smoke contains many mutagenic and carcinogenic chemicals that may be associated with mutations in tumor suppressor genes such as p53 [10]. Suzuki and colleagues [10] reported that tumors with p53 mutations exhibited an increased growth rate, which could explain why patients with greater than 20 PY smoking history resulted in poorer outcomes compared with patients with 20 or less PY smoking history. Thus a history of heavy smoking can be a simple clinical indicator for poor postoperative prognosis in patients because of its biologic aggressiveness and invasiveness.

Prognosis of lung cancer patients has been predicted reliably by disease stage [11]. However, other candidate prognostic factors in addition to stage of disease also warrant consideration [12]. One of the most important and fundamental biologic factors is gender. In our group, the survival of elderly patients with stage I NSCLC is closely related to gender. A number of studies have reported that women with NSCLC live significantly longer than men after surgical or non-surgical treatment [13-15]. Several confounding factors associated with gender may influence survival in NSCLC. One representative factor is a difference in smoking status between genders. Smoking behavior is closely associated with social custom, and female/male smoking ratios are quite different between various regions and years of publication $[16,17]$. Because smoking may be the worst prognostic factor in lung cancer $[18,19]$, differences in smoking status prevalence could result in significant differences in survival outcome between genders.

However, some problems of our study are as follows. This study was retrospective, and surgery was performed in a selection-biased population. Reporting inaccuracies and other subtle selection biases are possible and may distort the results of the study. Secondly, sublobar resection cannot provide as much information for a final staging as lobectomy. Third, we should recognize that such retrospective analyses were inherently affected by predilections for several patients' factors between the types of surgery and the selection bias associated with surgical procedure. The lobectomy group may comprise younger patients and had a different racial mix. It is possible that healthier patients instead of sicker patients were offered lobectomy resection. These are known to be favorable prognostic factors in these patients.

In conclusion, sublobar resection in the elderly provides a long-term outcome which is equivalent to that obtained after standard lobectomy. Thus in patients who cannot tolerate a lobectomy, a lung-sparing procedure, such as wedge resection and segmentectomy, also appears to offer survival benefit. However, a large sample study with matching patients is necessary to confirm the equivalent results between the two surgical procedures.

\section{Authors declare no conflict of interest.}

\section{References}

1. Pirozynski M. 100 years of lung cancer. Respir Med 2006; 100: 2073-84.

2. Crinò L, Weder W, van Meerbeeck J, Felip E. Early stage and locally advanced (non-metastatic) non-small-cell lung cancer: ESMO Clinical Practice Guidelines for diagnosis, treatment and follow-up. Ann Oncol 2010; 21 (Suppl 5): v103- v115.

3. Scott WJ, Howington J, Feigenberg S, Movsas B, Pisters K; American College of Chest Physicians. Treatment of non-small cell lung cancer stage I and stage II: ACCP evidence-based clinical practice guidelines (2 ${ }^{\text {nd }}$ edition). Chest 2007; 132 (3 Suppl): 234S-42S.

4. Okami J, Ito Y, Higashiyama M, Nakayama T, Tokunaga T, Maeda J, Kodama K. Sublobar resection provides an equivalent survival after lobectomy in elderly patients with early lung cancer. Ann Thorac Surg 2010; 90: 1651-6.

5. Goldstraw P, Crowley J, Chansky K, et al. The IASLC Lung Cancer Staging Project: proposals for the revision of the TNM stage groupings in the forthcoming (seventh) edition of the TNM classification of malignant tumours. J Thorac Oncol 2007; 2: 706-14.

6. Ferlay J, Shin HR, Bray F, Forman D, Mathers C, Parkin DM. Estimates of worldwide burden of cancer in 2008: GLOBOCAN 2008. Int J Cancer 2010;127: 2893-917.

7. Blanchard EM, Arnaoutakis K, Hesketh PJ. Lung cancer in octogenarians. J Thorac Oncol 2010; 5: 909-16.

8. Birim O, Zuydendorp HM, Maat AP, Kappetein AP, Eijkemans MJ, Bogers AJ. Lung resection for non-small-cell lung cancer in patients older than 70: mortality, morbidity, and late survival compared with the general population. Ann Thorac Surg 2003; 76: 1796-801.

9. Pfeifer GP, Denissenko MF, Olivier M, Tretyakova N, Hecht SS, Hainaut P. Tobacco smoke carcinogens, DNA damage and p53 mutations in smoking-associated cancers. Oncogene 2002; 21: 7435-51.

10. Ishida H, Irie K, Itoh T, Furukawa T, Tokunaga O. The prognostic significance of $\mathrm{p} 53$ and bcl-2 expression in lung adenocarcinoma and its correlation with Ki-67 growth fraction. Cancer 1997; 80: 1034-45.

11. Mountain CF. Revisions in the international system for staging lung cancer. Chest 1997; 111: 1710-7.

12. Brundage MD, Davies D, Mackillop WJ. Prognostic factors in nonsmall cell lung cancer: a decade of progress. Chest 2002; 122: 1037-57.

13. Albain KS, Crowley JJ, LeBlanc M, Livingston RB. Survival determinants in extensive-stage non-small-cell lung cancer: the Southwest Oncology Group experience. J Clin Oncol 1991; 9: 1618-26.

14. Paesmans M, Sculier JP, Libert P, et al. Prognostic factors for survival in advanced non-small-cell lung cancer: univariate and multivariate analyses including recursive partitioning and amalgamation algorithms in 1,052 patients. The European Lung Cancer Working Party. J Clin Oncol 1995; 13: 1221-30. 
15. Ouellette D, Desbiens G, Emond C, Beauchamp G. Lung cancer in women compared with men: stage, treatment, and survival. Ann Thorac Surg 1998; 66: 1140-3.

16. Zang EA, Wynder EL. Smoking trends in the United States between 1969 and 1995 based on patients hospitalized with non-smoking-related diseases. Prev Med 1998; 27: 854-61.

17. Tyczynski JE, Bray F, Parkin DM. Lung cancer in Europe in 2000: epidemiology, prevention, and early detection. Lancet Oncol 2003; 4: 45-55.

18. Guo NL, Tosun K, Horn K. Impact and interactions between smoking and traditional prognostic factors in lung cancer progression. Lung Cancer 2009; 66: 386-92.

19. Toh CK, Gao F, Lim WT, et al. Never-smokers with lung cancer: epidemiologic evidence of a distinct disease entity. J Clin Oncol 2006; 24: 2245-51.

\section{Address for correspondence}

\section{Hongxu Liu MD}

Department of Thoracic Surgery

First Hospital, China Medical University

Shenyang 110001, China

tel. 86-158 4011 8434,

fax 86-24-2281 5632

e-mail: 237267352@qq.com

Submitted: 28.06 .2013

Accepted: $\quad 5.09 .2013$ 